\title{
FGFR2B Overexpression
}

National Cancer Institute

\section{Source}

National Cancer Institute. FGFR2B Overexpression. NCI Thesaurus. Code C159871.

An indication that overexpression of FGFR2B has been detected in a sample. 